\title{
Demand for Money in a Stochastic Environment
}

\author{
Joseph Atta-Mensah \\ Capacity Development Division, United Nations Economic Commission for Africa, Addis Ababa, Ethiopia \\ Email: atta-mensahj@uneca.org
}

How to cite this paper: Atta-Mensah, J. (2018) Demand for Money in a Stochastic Environment. Journal of Mathematical Finance, 8, 241-265. https://doi.org/10.4236/jmf.2018.82017

Received: February 6, 2018

Accepted: March 27, 2018

Published: March 30, 2018

Copyright (c) 2018 by author and Scientific Research Publishing Inc. This work is licensed under the Creative Commons Attribution International License (CC BY 4.0).

http://creativecommons.org/licenses/by/4.0/

\begin{abstract}
The author re-examines the demand-for-money theory in an intertemporal optimization model. The demand for real money balances is derived to be a function of real income and the rates of return of all financial assets traded in the economy. Unlike the traditional money-demand relation, however, where the elasticities are assumed to be constant, the coefficients of the explanatory variables are not constant and depend on the degree of an agent's risk aversion, the volatilities of the price level and income, and the correlation of asset returns. The author shows that the response of households to increased volatilities in the financial markets, economic activity, and prices cannot be predicted, because a rise in general uncertainties has an ambiguous impact on the demand for money. This suggests that increased uncertainty is not very helpful for the planning decisions of households, because the optimal level of money holdings in the period of uncertainty cannot be ascertained.
\end{abstract}

\section{Keywords}

Monetary Policy, Demand for Money, Portfolio Theory and Financial Engineering

\section{Introduction}

The theory of demand-for-money balances constitutes an important part of monetary economics ([1], chapter 13), who introduced the theory into economics, theorizes that economic agents hold money for precautionary, transactions, and speculative purposes. Both the precautionary and transactions demands are formulated as functions of income, whereas the speculative demand for money is influenced by the rate of return on traded securities. [2] describes the microeconomic underpinnings of the Keynesian transactions demand for money. Using an inventory-control model, he derives the now-famous "square root rule" for calculating the optimum level of money that must be held by households for 
transactions purposes. [3] describes the microeconomic foundations for the speculative demand for money. Applying the mean-variance analysis of the capital-asset-pricing model (CAPM), he shows that the demand for money depends on the expected return and riskiness of traded assets. ${ }^{1}$

Most of the theoretical derivations of the demand for money in the literature have been carried out in a static partial-equilibrium framework, in which economic agents choose the level of cash holdings that will minimize transactions costs. There are weaknesses to this framework. First, it assumes that the future rate of return of the financial assets is known with certainty. Second, economic agents do not undertake investment and consumption decisions simultaneously. Third, it is very difficult to understand the factors that make the traditional demand functions unstable. Fourth, the model is inadequate to analyze the impact of economic uncertainty on the demand for money. Fifth, the traditional models are static and do not allow for intertemporal substitution of financial assets. Sixth, empirical extensions assume that the parameters of the demand-formoney functions are constant and do not change over time.

This paper re-examines the theory of the demand for money by households, in a framework where an infinitely lived representative household simultaneously chooses an optimum level of consumption bundle and holdings of money, equities, and bonds. The source of income for the agent is the return on their financial assets and wage income. The prices of the consumption bundle, $\mathrm{P}$, the wage income, and the return on the financial assets (equities and bonds) are assumed to change stochastically. The demand functions for money and the two assets are derived. Factors that influence the demand for money are then examined.

Our results clearly show that, besides the traditional variables, the quantity of money held depends on an agent's aversion to risk, the rates of return of all assets in the economy, the riskiness of the assets, and the volatilities of the price level and income. Contrary to the traditional approach, which suggests that the demand function is linear, our framework indicates that the function is non-linear and that the parameters are not constant, which may explain the observed instability of estimated money-demand functions. Furthermore, our analysis demonstrates how changes in an agent's preferences have an impact on the quantity of money holdings, an important result that the traditional framework does not capture.

In order to have a better understanding of the demand for money a central bank needs to know what constitute money. Unfortunately, neither the literature on monetary economics nor traditional textbooks provide an adequate definition of money. Textbooks usually focus on the four main functions performed by money: medium of exchange, store of value, unit of account and standard of deferred payment. However, financial innovations have fundamentally altered

${ }^{1}$ For other theoretical and empirical work on the demand for money, see [4] [5] and [6]. Also see Laidler (1993) for a survey on issues related to the demand for money. Recent work on this subject can be found in [7] [8] [9] [10] [11] and [12]. 
the characteristics of many monetary assets so that these functional definitions of money are inadequate. Furthermore, the several uses of money make it difficult to have a unique definition of money. A pragmatic approach requires describing money in a manner that will allow for multiple definitions of money. Thus, money could be defined to be assets accepted for transactions or to be a broad measure of fairly liquid assets.

The paper begins in Section 2 with discussions on the various definitions of money proposed in the literature. The rest of the paper is organized as follows. Section 3 presents a simple theoretical derivation of a money-demand function. Section 4 analyses the factors that influence the demand for money. Section 5 offers some conclusions.

\section{Definition of Money}

For a century, economists have been trying without success to develop a single definition of money that would gain acceptance within the discipline. This what [13] in 1899 had to say:

It is a singular and, indeed, a significant fact that, although money was the first economic subject to attract men's thoughtful attention, and has been the focal centre of economic investigation ever since, there is at the present day not even an approximate agreement as to what ought to be designated by the word. The business world makes use of the term in several senses, while among economists there are almost as many different conceptions as there are writers upon money. ([13], p. 219)

In attempting to define money, different economists have focused on the particular functional properties that they consider important. As a result, a wide range of definitions exists in the literature. This section of the paper discusses several of these definitions in the light of recent financial innovations. The definitions examined characterize money in the following ways: as a tangible medium-of-exchange, as a liquid asset, as a means-of-payment, as assets highly correlated with GNP, and as assets with a stable demand function.

\section{Money as a tangible medium-of-exchange}

[14] and [15] implicitly define money as a tangible (physical) medium-ofexchange. This definition excludes all assets accepted for transaction other than currency. This definition is very restrictive. In fact, only a small proportion of the dollar value of purchases is paid for with currency. Transaction balances in chartered banks and near banks serve the same function as currency in paying for goods and services. Payments can be made with cheques and electronic transfers. This payment system involves debiting buyers' bank accounts and

${ }^{2}$ Credit cards are also accepted for payments of goods and services. However, the line of credit to bearers of the cards should not qualify as money. Institutions that issue the cards pay sellers for the goods and services that bearers purchase. The payment system also involves debiting the bank accounts of the credit card companies and crediting sellers' accounts. In effect, cardholders borrow from the card company any time they charge the card. A loan is retired whenever the cardholder settles his or her balances in full. 
crediting sellers' accounts by amounts equal to the value of transactions. ${ }^{2}$ In essence, these forms of payments involve an accounting system of exchange that operates through debits and credits to bank accounts; no physical medium-ofexchange (currency) is required.

Given the functions of transaction balances, tangibility is not an appropriate criterion for the definition of money. Although we cannot physically observe transaction balances, they perform the same functions as currency. Hence both transaction balances and currency must be called money. ${ }^{3}$

\section{Money as liquid assets}

Other economists define money as liquid assets. However, the concept of liquidity is very difficult to define. [16] in his Treatise on Money talks about an asset being liquid if it can be "realizable at short notice without loss." Another definition of liquidity, which is contained in [17] and [18], is: "the ability to sell an asset on demand (more precisely, within a specified time interval) for a nominal sum fixed in advance (i.e., to convert the asset into a fixed nominal number of units of "money")." A third view relates liquidity to spending by economic agents. [19] claims that:

It is the whole liquidity position that is relevant to spending decisions, .... A decision to spend depends not simply on whether the would-be spender has cash or "money in the bank", although that maximum liquidity is obviously the most favourable springboard. There is the alternative of raising funds either by selling an asset or borrowing; and the prospects of a cash flow from future sales of a product both encourages commitment beyond immediately available cash and makes borrowing easier. ... spending is not limited by the amount of money in existence; but it is related to the amount of money people think they can get hold of, whether by receipts of income (for instance from sales), by disposal of capital assets or by borrowing. ${ }^{6}$

It is difficult to accept any of the three views as an unequivocal definition of liquidity. [16] suggests that liquid assets must be realizable without loss. By realizability, [16] is referring to assets that can be sold quickly at their current price. This definition is too narrow in that it tends to exclude assets which cannot be transferred to a third party. According to [16], Government Savings Bonds (GSB) would not be considered liquid. However, although secondary markets do not exist for GSBs, they are redeemed instantaneously by the government on demand. This is also the case with products sold by the chartered banks, such as Guarantee Investment Certificates (GICs), Registered Retirement

${ }^{3}$ It should be noted that currency has a wider acceptability than cheques. Personalized cheques may not be accepted by some sellers of goods and services. In the same vein, paper notes are completely useless for purchasing items from some vending machines. These points may bias the measurement of money.

${ }^{4}$ See Keynes ([16], p.67)

${ }^{5}$ See ([18], p.129). [18] also suggest that the implication of this definition is that the nominal sum fixed in advance is equal to or close to the sum paid for the asset.

${ }^{6}$ See [19], sections 389 and 390, pp. 132-133. 
Savings Plans (RRSPs), Money Market Mutual Funds (MMMFs), which although not tradeable can be redeemed instantaneously at the source of purchase. $^{7}$ Another shortcoming of [16] definition of liquidity is that it excludes marketable assets, such as stocks, Treasury-bills and corporate bonds, which can be sold at a loss prior to the maturity dates. ${ }^{8}$

The definition of liquidity found in [18] is very restrictive. The definition implies that all liquid assets can be sold instantaneously on demand. An implication of the definition is that assets are traded in fairly efficient markets with future prices of assets known to investors. Thus, the definition excludes assets which cannot be sold instantaneously or whose future prices are unknown. Financial products like GSBs, GICs, RRSPs, MMMFs and Savings and demand deposit accounts cannot be sold on demand to a third party since there are no secondary markets for them. These assets cannot be classified as liquid assets according to [18]. Furthermore, according to the definition, stocks and corporate bonds redeemed before the maturity dates are not liquid because their future values are not known.

[19] definition of liquidity suggests that all assets be treated as money. According to the definition, real estate must be seen as a liquid asset since economic agents can dispose of their real estate in order to obtain goods and services. The definition also allows for the inclusion of credits, since credits are also spent on goods and services. This definition is not totally acceptable because the measure of liquidity is too broad.

From the three definitions of liquidity, one might logically conclude that for an asset to be liquid it must possess the following characteristics. First, the nominal value of the asset must be fairly predictable; second, the asset must be realizable; and third, the asset must be reversible. ${ }^{9}$

An asset is predictable if the nominal future value is known with certainty. In other words, a predictable asset is riskless in nominal terms. The nominal value of currency is perfectly predictable. The nominal value of foreign currencies held outside the countries of origin is not predictable under flexible exchange regimes. Marketable government bonds are predictable if held till the maturity dates. However, the further away the maturity dates of the bonds, the less predictable are their current nominal values. Also, the future value of other assets, such as common stocks, real estate, and precious metals, cannot be predicted accurately.

Realizability refers to the ability to sell an asset at its current price. Assets that are widely traded in organized markets are very realizable. The use of modern technology in stock markets permits the instantaneous sale of stocks to a large number of buyers on various stock exchanges. This kind of market makes common stocks very realizable. On the other hand, master paintings are not realizable since the sale of the paintings takes place in a thin market.

Reversibility refers to the spread between the buying and selling price of an

${ }^{7}$ These financial instruments are generally found in Canada. Similar types exist in other countries. ${ }^{8}$ See [20] for other views that question [21] definition of liquidity.

${ }^{9}$ See $[21]$ for a useful discussion of these properties. 
asset. The spread reflects transaction costs, such as taxes, time required to effect the transaction, brokerage fees, lawyers' fees, etc. Currency is perfectly reversible. GSBs are almost reversible. Stocks, government and corporate bonds and real estate are less reversible compared to currency. The degree of reversibility of the asset depends on the size of the transaction.

This analysis implies that for assets to be called money they must be fairly predictable, instantaneously realizable and fairly reversible.

\section{Money as a means-of-payment}

This sub-section presents three views on how money might be defined as a means-of-payment. [22] suggests that in addition to currency and demand deposits, all types of credits must be regarded as money. Finding [22] definition too broad, [23] proposes that money should be defined to include currency, demand deposits and bank overdrafts. Disagreeing with [22] and [23] [24] proposes a narrow definition of money which consists of currency and demand deposits.

\section{Clower's definition of money}

[22] proposes that money be defined to consist "of the class of all commodities that serve as means of payment in organized markets." ${ }^{10}$ [22] sees a monetaryexchange economy as a system that allows the existence of a set of independent markets. In each market, units of one particular commodity can be traded directly for units of other commodities that custom or law permits as means of payment.

[22] proposed definition of money is derived from a comparison of a monetary economy with Walrasian auction markets. [22] argues that a Walrasian equilibrium analysis assumes one organized market where all commodities traded within that market are accepted as means of payment. ${ }^{11}$ However, unlike a Walrasian economy in which there is only one centralised market, a money economy involves decentralised markets. [22], therefore, suggests that money must be defined in terms of the special role assigned to certain commodities as payment-media in organized markets.

[22] suggests that "money" must be defined to include currency, demand deposits and all forms of credit available to economic agents. He buttresses this claim by arguing that:

The essential issue here is whether the tender of any given financial instrument permits a buyer to take delivery of a commodity from a seller. On this criterion, trade credit qualifies as money-trade credit being interpreted to include credit card and overdraft facilities, department store credit and travellers' checks, as well as commercial paper and book credits. On the same criterion, time deposits and other financial claims that are perfect or near-perfect substitutes for money only as stores of value unambiguously fail to qualify as money. ${ }^{12}$ 
Although [22] is correct in defining money in terms of means of payment, it is questionable whether any type of credit can be included as part of money. For instance, trade credits allow economic agents to defer final payments of goods and services. Consider this example. A bakery receives $\$ 1000$ worth of flour from a flour mill. Let us assume that the mill grants the bakery a credit for 120 days. Following [22] definition, the bakery must be perceived to have $\$ 1000$ of money on the date that it received the credit from the mill; it is this money that enabled the bakery to take delivery of the flour. However, it would be misleading to accept the credit of $\$ 1000$ as money. In a monetary-exchange economy, economic agents exchange goods and services for a particular commodity, called money, and vice versa. The exchange model does not deal with the length of time required for the completion of the exchange. Some contracts require that the exchange of money for goods and services be carried out instantaneously. For example, the bakery would want to receive money for every loaf of bread sold to customers. In such a contract the delivery and the payment times coincide. Other contracts, like the one between the bakery and the mill, separate the delivery and payment dates; the exchange of flour for money is completed at the end of the 120 days.

Similar to trade credits, credit cards should not be considered part of the money stock. Using the same analogy as the example dealing with the bakery, the use of credit cards involves a tripartite exchange. The credit card companies complete the exchange between cardholders and suppliers of goods and services. The contract between cardholders and the card-issuing companies involves cardholders exchanging money for the provision of credit services by the companies. This exchange, whose delivery and payment time periods do not coincide, is completed when cardholders retire all the debt owed to the company. The arguments against [22] form the basis of the next definition of money by [23].

\section{Shackle's definition of money}

In his critique of [22] definition of money, [23] defines money as "the means of strictly simultaneous payment." ${ }^{13} \mathrm{He}$ suggests that the money stock must include only assets that serve to make payments for goods and services. The money stock must, therefore, include currency, demand deposits, and time deposits that permit holders to draw cheques. Other time deposits with no chequing privileges must not be part of the money stock.

[23] excludes trade credits from the money stock. He views credits as the deferment, not completion, of payment. However, he suggests the addition of bank overdrafts to money stock. He argues that overdrafts are different from trade credits. He points out that, like chequing accounts, overdrafts enable economic agents to complete the payment for goods and services, whereas trade credit postpones the completion of the payments.

The view by [23] that the stock of money should include bank overdrafts is unacceptable. This view contradicts his position that trade credits are not part of the money supply. As pointed out in [25], one has to make a distinction between

\footnotetext{
${ }^{13}$ See $([23]$, p.32).
} 
trade credits and bank overdrafts. The distinction stems from differences between the goods and services market and the debt (loan) market. Reconsider the example of the bakery and the flour mill. The bakery receives a trade credit and pays the mill 120 days later. This trade can be conceptualized as involving three transactions. In the first transaction, the bakery purchases $\$ 1000$ worth of flour from the mill. Instead of receiving immediate payment for the flour, the mill gets into a second transaction whereby it agrees to purchase at par a "bond" (debt instrument) from the bakery; the "bond", with a face value of $\$ 1000$ matures in 120 days from the date of delivery of the flour. The third transaction takes place in 120 days when the bakery redeems the "bond"; in other words, the bakery pays the mill. Following [23] definition, the exchange of flour for money took place in the first transaction. The proceeds from the flour sale were instantaneously used by the mill, in the second transaction, to purchase the "bond" from the bakery. The third transaction involved the exchange of money for the "bond." The implication of [23] definition is that money is what is used in the completion of payment for goods and services. Whatever is used as the means of payment in the "bond" or debt market must not be counted as money. According to this analysis, money appeared in the first transaction but not in the second or third transactions.

Consider another example that now has the bakery paying the flour mill from a line of credit (overdraft) obtained from a bank. Let us assume that the overdraft must be paid in 120 days. This example also involves three transactions. In the first transaction, the bank purchases from the bakery a "bond" that matures in 120 days and has a face value of $\$ 1000$. The revenue from the sale of the "bond" is instantaneously transferred into the bakery's bank account. In the second transaction, the bakery takes delivery of the flour and simultaneously pays the mill with a cheque for $\$ 1000$ drawn on its bank account. The third transaction occurs in 120 days when the bakery buys back the "bond" from the bank; in other words, the bakery pays the overdraft. In this second example money appears in the second transaction but not in the first or third transactions. It follows from the analysis that overdrafts perform the same function as trade credits. Hence, by the same argument used against the inclusion of trade credits in the money stock, overdrafts should not qualify as part of the money stock.

\section{Johnson's definition of money}

In opposition to [22], [24] defines money as assets that can be exchanged for goods and services without incurring a debt and a repayment obligation. [24] agrees with [22] that unused overdraft facilities or unused trade credits enable economic agents to purchase goods and services that could not have been obtained from the agents' flow of income. However, [24] notes that, unlike the use of money balances, the use of overdrafts or trade credits results in a debt that eventually must be repaid.

[24] definition implies that currency, demand deposits and time deposits with chequing privileges are money. Travellers' cheques would also be classified as money by [24] since they are accepted in exchange for goods and services and do 
not create obligations. In the same vein, debt can be used as money by the issuer if (like coins and notes issued by central banks) it never has to be repaid.

If money is defined as assets that serve as means-of-payment, then [24] definition is acceptable. The definition separates the debt (bond) market from the goods and services market. Money is therefore defined as assets that are accepted as means of payment in the goods market. However, it excludes time deposits which do not involve chequing privileges.

\section{Money as assets highly correlated with GNP}

[26] propose that money be defined as the set of liquid financial assets that are highly correlated with aggregate economic activity, such as income. Using this definition, [26] find the sum of currency, demand deposits and time deposits at commercial banks to be more highly correlated with income than narrower definitions of money.

The implication of [26] proposal is that the definition of money rests on its empirical performance. The definition therefore provides flexibility for central banks to include in the monetary aggregates financial assets that help increase the correlation between the aggregates and the proxy for economic activities.

The definition is however not fully satisfactory. First, the definition does not consider other criteria, such as the substitutability, information content and stability, used to assess the empirical performance of the financial assets.

A second criticism of the definition concerns the importance of correlations. Let us imagine a study that finds the correlation between a portfolio of financial assets and income higher than that between income and M1 or M2. According to the definition of [26], this portfolio of assets should be considered more money-like than M1 or M2. This presents a weakness in the definition. The portfolio may be correlated with income due to some fundamentals of the economy which do not characterize the role of money in the economy.

Third, even if one accepts a definition that correlates money with income, it will be difficult for central banks to find the "money" stock that they may use to influence economic activity. The statistical relationships between money and income could be due to shocks from demand and supply functions of money. Economic agents may respond to actions of monetary authorities; the authorities may also be responding to economic activities. These responses may affect the behaviour of banks, firms, households and policy makers. It would be a difficult task for a central bank to find a collection of liquid assets that best correlate with income and then use this collection to influence economic activities. ${ }^{14}$ In other words monetary policy-makers will be faced with the problem described in the

\footnotetext{
${ }^{14}[27]$ provides a useful critique of [26] definition.

${ }^{15}$ [28] explains that a common practice of some macroeconomists is to estimate a model of the economy and then evaluate different policy options by using their model to work out what will be the results of the various different policies. On the basis of this procedure the economist can then offer advice about the desirability of the different policy options. An assumption implicit in this procedure is that the econometrician has successfully estimated the "constant structure" of the economy, and that this estimated structure of the model will not be different under different policies. Thus, the structure of the model is policy invariant.
} 
literature as the "Lucas critique."15

[29] also finds some drawbacks to the definition. [29] studied the lead-lag relationships between groups of liquid assets and national income. The study finds M2 to be highly correlated with two or more lagged values of income. The sum of currency and demand deposits is found to be correlated with current or quarter lag values of income. These results show that the criterion chosen by [26] to define money does not necessarily lead to unambiguous results.

Although the definition proposed by [26] is found not to be fully satisfactory, it forms the basis toward an empirical definition of money that could serve as useful guides for the conduct of policy by central banks. An empirical definition would provide flexibility for central banks to define money in a manner that includes financial assets that are assessed to perform empirically well, based on a chosen criterion.

\section{Money as assets with a stable demand function}

[30] suggests that money can be defined in terms of its stable demand function. He notes that a stable demand function makes the consequences of changes in the money supply by monetary authorities more easily and accurately predictable. In other words, a stable function allows authorities to use the money supply to effectively influence the level of economic activity.

Like [26] [30] proposed definition leads towards an empirical definition of money. However, there are some drawbacks to [30] definition. The definition begs the question of what money actually is. How does one determine the stability of the demand for money when there is no clear definition of money itself?

Let us assume, however, that a proper definition of money was known. The next problem to be addressed would be finding a unique demand for the money function. Several demand functions exist in the literature, however. Which of these functions should serve as the "demand function of money" if two or more of the functions are stable?

[31] have also criticized the estimation of demand for money functions on the following grounds. First, they argue that current economic theory does not produce a unique money-demand function that is very robust. This theory does not specify the nature of the regression equation. Second, since there is no proper theory of demand for money, researchers have great latitude for data "mining" and specification searches. Consequently, the estimated coefficients of the money-demand functions are closely related to the idiosyncrasies of the data for the sample period. It is therefore not surprising if the estimated demand-functions perform badly in an out-of-sample forecast.

The preceding section demonstrated how difficult it is to define money precisely. Indeed, a universal definition may be beyond our grasp. As noted by [18]:

the definition of money is to be sought for not on grounds of principle but on grounds of usefulness in organizing our knowledge of economic relationships. "Money" is that to which we choose to assign a number by specified operations; it is not something in existence to be discovered, like the 
American continent; it is a tentative scientific construct to be invented, like

"length" or "temperature" or "force" in physics."16

In the absence of a universal definition, central banks should define "money" pragmatically in a manner that will help them conduct a sound and effective monetary policy. Based on the discussions on various definitions of money presented, central banks could define "money" to include assets that are accepted as means-of-payment, liquid assets and other types of liabilities held by financial institutions. These assets need not be tangible but when used should not generate debt or a repayment obligation. Such a definition excludes from the money stock all forms of credits. Furthermore, based on a chosen criterion, these assets should perform empirically well.

\section{A Simple Derivation of a Demand-for-Money Function}

Despite the challenges presented in Section 2, in this Section, we apply the framework of portfolio theory to derive a theoretical expression for the quantity of money that economic agents are willing to hold. ${ }^{17}$ In this framework, households are assumed to choose simultaneously the optimum level of consumption bundle, money (currency, or transactions money), equities, and bonds.

\subsection{The Growth Rates of Financial Assets and the Price Level}

Let $M, S$, and $B$, respectively, represent the market value of the portfolio of money, equities, and bonds. The nominal rates of return of the financial assets and the price of the consumption good, $P$, are assumed to follow a stochastic process of the form:

$$
\begin{gathered}
\frac{\mathrm{d} M}{M}=\alpha_{m} \mathrm{~d} t \\
\frac{\mathrm{d} S}{S}=\alpha_{s} \mathrm{~d} t+\sigma_{s} \mathrm{~d} z_{s} \\
\frac{\mathrm{d} B}{B}=\alpha_{b} \mathrm{~d} t+\sigma_{b} \mathrm{~d} z_{b} \\
\frac{\mathrm{d} P}{P}=\alpha_{p} \mathrm{~d} t+\sigma_{p} \mathrm{~d} z_{p}
\end{gathered}
$$

where $\alpha_{m}$ is the expected instantaneous rate of return on money, $\alpha_{s}$ is the expected instantaneous rate of return on equities, $\sigma_{s}$ is the instantaneous standard deviation of the return on equities, $\alpha_{b}$ is the expected instantaneous rate of return on bonds, $\sigma_{b}$ is the instantaneous standard deviation of the return on bonds, $\alpha_{p}$ is the expected instantaneous rate of inflation, and $\sigma_{p}$ is the instantaneous standard deviation of the inflation rate. ${ }^{18}$ Also, $\mathrm{d} z_{s}, \mathrm{~d} z_{b}$, and $\mathrm{d} z_{p}$ are standard Wiener processes with the following properties: $E\left(\mathrm{~d} z_{s}\right)=0 ; E\left(\mathrm{~d} z_{s}\right)^{2}=\mathrm{d} t$; $E\left(\mathrm{~d} z_{b}\right)=0 ; \quad E\left(\mathrm{~d} z_{b}\right)^{2}=\mathrm{d} t ; \quad E\left(d z_{p}\right)=0 ; \quad E\left(d z_{p}\right)^{2}=d t ; \quad E\left(d z_{s} d z_{p}\right)=\rho_{s p} d t ;$

${ }^{16}$ See ([18], p. 137). A good discussion can be found in [17] as well.

${ }^{17}$ See [32], [33] and [34] on the methodology we follow.

${ }^{18}$ Note that $\alpha_{m}$ is the average interest paid on the components of M1. 
$E\left(d z_{b} d z_{s}\right)=\rho_{b s} d t$; and $E\left(\mathrm{~d} z_{b} \mathrm{~d} z_{p}\right)=\rho_{b p} \mathrm{~d} t$; where $\mathrm{d} t$ is the change in time, $\rho_{s p}$ is the instantaneous correlation between equity and the inflation rate, and $\rho_{b p}$ is the instantaneous correlation between bonds and the inflation rate. ${ }^{19}$

The nominal rate of return on money, expressed by Equation (1), has been modelled to be deterministic to reflect the liquidity and the predictable return of currency or transactions money in general. This implies that the definition of money in this paper excludes mutual funds, which are found in broad monetary aggregates. The return on bonds (Equation (3)) is modelled to capture the stochastic behaviour of interest rates. The rate of inflation, in our framework, is also assumed to be stochastic. Equation (4) therefore captures the stochastic behaviour of the price level.

In an inflationary economy, economic agents are more concerned with the real return on an asset than the nominal return. Defining the real values of money, equities, and bonds, respectively, as $m=M / P, s=S / P$, and $b=B / P$, it is shown in the appendix that the real returns of the assets in the economy are:

$$
\begin{gathered}
\frac{\mathrm{d} m}{m}=\beta_{m} \mathrm{~d} t-\sigma_{p} \mathrm{~d} z_{p} \\
\frac{\mathrm{d} s}{\mathrm{~s}}=\beta_{s} \mathrm{~d} t+\sigma_{s} \mathrm{~d} z_{s}-\sigma_{p} \mathrm{~d} z_{p} \\
\frac{\mathrm{d} b}{b}=\beta_{b} \mathrm{~d} t+\sigma_{b} \mathrm{~d} z_{b}-\sigma_{p} \mathrm{~d} z_{p}
\end{gathered}
$$

where

$$
\begin{gathered}
\beta_{m}=\alpha_{m}-\alpha_{p}+\sigma_{p}^{2} \\
\beta_{s}=\alpha_{s}-\alpha_{p}-\sigma_{s p}+\sigma_{p}^{2} \\
\beta_{b}=\alpha_{b}-\alpha_{p}-\sigma_{b p}+\sigma_{p}^{2}
\end{gathered}
$$

$\sigma_{s p}$ and $\sigma_{b p}$, which are, respectively, the covariances between the nominal rate of return on equities and the inflation rate, and the nominal rate of return on bonds and the inflation rate, are defined as:

$$
\begin{gathered}
\sigma_{s p}=\rho_{s p} \sigma_{s} \sigma_{p} \\
\sigma_{b p}=\rho_{b p} \sigma_{b} \sigma_{p}
\end{gathered}
$$

Equations (8) to (10) generalize the Fisher equation and therefore give a more accurate estimation of real rates than the traditional estimation. Note that if inflation is deterministic, then the usual Fisher result-that the real return on an asset is equal to the difference between the nominal return and the inflation rate-will hold.

\subsection{Budget Constraint}

The household is assumed to generate wealth from capital gains and wage income. Let $\omega_{1}, \omega_{2}$, and $\omega_{3}$ be the proportions of the household's portfolio held in ${ }^{19}$ [35] describe the methodological and mathematical foundations of continuous-time stochastic modelling. 
bonds, equities, and money. The budget constraint, as a flow, in real terms could then be expressed as:

$$
\mathrm{d} W=\mathrm{d} Y+\omega_{1} W \frac{\mathrm{d} b}{b}+\omega_{2} W \frac{\mathrm{d} s}{\mathrm{~s}}+\omega_{3} W \frac{\mathrm{d} m}{m}-c \mathrm{~d} t
$$

where $W$ is the instantaneous total wealth of the household, in real terms, $c$ is the rate of consumption per unit time, and $Y$ is real labour income, which is modelled to follow a stochastic process: ${ }^{20}$

$$
\frac{\mathrm{d} Y}{Y}=\beta_{y} \mathrm{~d} t+\sigma_{y} \mathrm{~d} z_{y}
$$

where $\beta_{y}$ is the expected instantaneous average real wage rate, and $\sigma_{y}$ is the instantaneous standard deviation of the wage rate. Also, $\mathrm{d} z_{y}$ is a standard Wiener process with the following properties: $E\left(\mathrm{~d}_{y}\right)=0 ; E\left(\mathrm{~d} z_{y}\right)^{2}=\mathrm{d} t$; $E\left(\mathrm{~d} z_{y} \mathrm{~d} z_{s}\right)=\rho_{y s} \mathrm{~d} t ; E\left(\mathrm{~d} z_{y} \mathrm{~d} z_{p}\right)=\rho_{y p} \mathrm{~d} t$; and $E\left(\mathrm{~d} z_{y} \mathrm{~d} z_{b}\right)=\rho_{y b} \mathrm{~d} t$. Moreover, $\mathrm{d} t$ is the change in time; $\rho_{y s}$ is the instantaneous correlation between the wage rate and equity; $\rho_{y p}$ is the instantaneous correlation between the wage rate and the inflation rate; and $\rho_{y b}$ is the instantaneous correlation between the wage rate and the bond rate.

Also, the following condition must be met:

$$
\omega_{1}+\omega_{2}+\omega_{3}=1
$$

Substituting Equations ((5)-(7), and (14)) into Equation (13), and using Equation (15) to express $\omega_{3}=1-\omega_{1}-\omega_{2}$, the agent's intertemporal budget constraint takes the form:

$$
\begin{aligned}
\mathrm{d} W= & \omega_{1} W\left(\beta_{b}-\beta_{m}\right) \mathrm{d} t+\omega_{2} W\left(\beta_{s}-\beta_{m}\right) \mathrm{d} t+\left(\beta_{m} W-c\right) \mathrm{d} t+\beta_{y} Y \mathrm{~d} t \\
& +\omega_{1} W \sigma_{b} \mathrm{~d} z_{b}+\omega_{2} W \sigma_{s} \mathrm{~d} z_{s}-W \sigma_{p} \mathrm{~d} z_{p}+Y \sigma_{y} \mathrm{~d} z_{y}
\end{aligned}
$$

\subsection{Household Maximization Problem}

The representative agent is faced with the problem of choosing a portfolio of assets and a consumption rule that will maximize the expected value of a von Neumann-Morgenstern utility function. Thus, the agent's optimization problem can be summarized as:

$$
\max _{c, \omega_{1}, \omega_{2}} E_{0}\left[\int_{0}^{\infty} \mathrm{e}^{-\rho t} U(c(t), t) \mathrm{d} t\right]
$$

subject to Equation (16), and

$$
W(0)=W_{0}
$$

Also, the utility function $U(\cdot, \cdot)$ is restricted to be concave in $c$ (i.e., $U_{c}>0$ and $\left.U_{c c}<0\right) . E_{0}$ is the conditional expectations operator conditional on $W(0)=W_{0}$ being known. A value function, $J$, is then defined as:

$$
J(W, Y, t) \equiv \max _{c, \omega_{1}, \omega_{2}} E_{0}\left[\int_{0}^{\infty} \mathrm{e}^{-\rho t} U(c(t), t) \mathrm{d} t\right]
$$

\footnotetext{
${ }^{20}$ In Equation (13), consumption could be modelled to follow a stochastic process. Such an approach, however, would only complicate the model and not change the final outcome of the results of the paper.
} 
Equation (19) is also constrained by Equations ((16) and (18)). As shown in the appendix, the optimization problem facing the agent could be reduced to:

$$
\max _{c, \omega_{1}, \omega_{2}} \Phi\left(c, \omega_{1}, \omega_{2}, W, Y, t\right)=\mathrm{e}^{-\rho t} U(c(t), t)+L(J)
$$

where $L$, which is known as the Dynkin operator over $W$ and $Y$, is defined in the appendix. The first-order conditions for the maximization problem are:

$$
\begin{gathered}
\Phi_{c}=\mathrm{e}^{-\rho t} U_{c}-J_{w}=0 \\
\Phi_{\omega_{1}}=W J_{w}\left(\beta_{b}-\beta_{m}\right)+W Y \sigma_{b y} J_{w y} \\
+J_{w w}\left[W^{2}\left(\omega_{1} \sigma_{b}^{2}+\omega_{2} \sigma_{b s}-\sigma_{b p}\right)+W Y \sigma_{b y}\right]=0 \\
\Phi_{\omega_{2}}=W J_{w}\left(\beta_{s}-\beta_{m}\right)+W Y \sigma_{s y} J_{w y} \\
+J_{w w}\left[W^{2}\left(\omega_{2} \sigma_{2}^{2}+\omega_{1} \sigma_{b s}-\sigma_{s p}\right)+W Y \sigma_{s y}\right]=0
\end{gathered}
$$

Equation (21) restates the condition that, in equilibrium, the marginal utility of consumption can be equated to the marginal utility of wealth. Equations ((22) and (23)) are similar to the standard equations for deriving a generalized capitalasset-pricing model.

\subsection{The Demand for Money}

Given that $\omega_{3}$ represents the proportion of real wealth held as money, the aggregate money held by the agent is $\omega_{3} W$, which is equated to a familiar notation, $M / P(\mathrm{~m})$. Based on Equation (A27), in the appendix, the relation for the demand for money can be expressed as:

$$
m=A_{0}+A_{1} \beta_{m}+A_{2} \beta_{s}+A_{3} \beta_{b}+A_{4} Y
$$

where

$$
\begin{gathered}
A_{0}=\frac{W\left[\sigma_{s} \sigma_{y}\left(1-\rho_{s b}^{2}\right)-\sigma_{p} \sigma_{s}\left(\rho_{b p}-\rho_{s b} \rho_{p s}\right)-\sigma_{p} \sigma_{b}\left(\rho_{p s}-\rho_{s b} \rho_{b p}\right)\right]}{W \sigma_{b} \sigma_{s}\left(1-\rho_{s b}^{2}\right)} \\
\begin{array}{c}
W \sigma_{b} \sigma_{s}\left(1-\sigma_{s}\left(\rho_{s b} \rho_{s y}-\rho_{b y}\right)+\sigma_{b}\left(\rho_{s b} \rho_{b y}-\rho_{s y}\right)\right] \\
A_{1}=-\frac{\left(J_{w} / J_{w w}\right)\left(\sigma_{s}^{2}-2 \rho_{s b} \sigma_{b} \sigma_{s}-\sigma_{b}^{2}\right)}{\sigma_{s}^{2} \sigma_{b}^{2}\left(1-\rho_{s b}^{2}\right)} \\
A_{2}=\frac{\left(J_{w} / J_{w w}\right)\left(\sigma_{b}^{2}-\rho_{s b} \sigma_{b} \sigma_{s}\right)}{\sigma_{s}^{2} \sigma_{b}^{2}\left(1-\rho_{s b}^{2}\right)} \\
A_{3}=\frac{\left(J_{w} / J_{w w}\right)\left(\sigma_{s}-\rho_{s b} \sigma_{b}\right)}{\sigma_{b}^{2} \sigma_{s}\left(1-\rho_{s b}^{2}\right)} \\
A_{4}=\frac{\left(J_{w} / J_{w w}\right) \sigma_{y}\left(\rho_{b y}\left(\sigma_{b} \rho_{s b}-\sigma_{s}\right)-\rho_{s y}\left(\sigma_{s} \rho_{s b}-\sigma_{b}\right)\right)}{\sigma_{b} \sigma_{s}\left(1-\rho_{s b}^{2}\right)}
\end{array}
\end{gathered}
$$

Before we examine the demand function for real money balances (Equation 
(24)), it is important to note that $\left(-J_{W} / J_{w W}\right)$ is the inverse of the household's degree of risk aversion. The degree of risk aversion is positive because of the concavity of the indirect utility function, which makes $J_{w W}<0$.

We then interpret $\left(J_{w y} / J_{w w}\right)$. From the first-order condition for consumption (Equation (21)), we have:

$$
\mathrm{e}^{-\rho t} U_{c c} \frac{\mathrm{d} c}{\mathrm{~d} y}=J_{w y}
$$

and

$$
\mathrm{e}^{-\rho t} U_{c c} \frac{\mathrm{d} c}{\mathrm{~d} w}=J_{w w}
$$

Expressing Equation (30) as a ratio of Equation (31), we have:

$$
\frac{J_{w y}}{J_{w w}}=\frac{\mathrm{d} c / \mathrm{d} y}{\mathrm{~d} c / \mathrm{d} w}
$$

Equation (32) suggests that $\left(J_{w y} / J_{w w}\right)$ is the ratio of the marginal propensity to consume out of income to the marginal propensity to consume out of wealth. The fact that these propensities are positive implies that $\left(J_{w y} / J_{w w}\right)$ is also positive.

Equation (24) appears to be similar in spirit to the traditional demand for money. It also corroborates Friedman's (1956) view that the demand for money is a function of the rates of return of all financial assets traded in the economy. Unlike the traditional money-demand relation, however, where the elasticities are assumed to be constant, the coefficients of the explanatory variables are not constant and depend on the degree of an agent's risk aversion, the volatilities of the price level and income, and the correlation of asset returns. The functional form of the demand function implies that taste, risk appetite, and macroeconomic uncertainty determine the quantity of money holdings by households. Contrary to empirical results in the literature, the derived demand function clearly shows that the elasticities of money demand are not constant. This may explain why the money-demand functions have been observed empirically to be unstable. The properties of the money-demand function are examined in Section 3.

\section{Factors That Influence the Demand for Money}

In Section 2, we derived an expression for the demand for money. Although we have presented the demand for real money balances (Equation (24)) in a linear form, we notice that it is a non-linear function of the rates of return and volatilities of the assets in the economy, the inverse of the degree of risk aversion and income. In this section, we examine the properties of this non-linear function.

Proposition 1: A rise in money's own rate of return leads to an increase in the real money holdings.

Proof: Differentiating the demand function (Equation (24)) with respect to $\beta_{m}$ yields: 


$$
\frac{\partial m}{\partial \beta_{m}}=-\frac{\left(J_{w} / J_{w w}\right)\left(\sigma_{s}^{2}-2 \rho_{s b} \sigma_{b} \sigma_{s}-\sigma_{b}^{2}\right)}{\sigma_{s}^{2} \sigma_{b}^{2}\left(1-\rho_{s b}^{2}\right)}>0
$$

since $\rho_{s b}<0$, because equity returns and bond yields are negatively related. Also, $\rho_{s b}^{2}<1$ and $\left(-J_{w} / J_{w w}\right)>0$.

Remarks. Proposition 1 does not need any further elaboration, because it is very intuitive. It suggests that, all things being equal, economic agents' holdings of money rise with the rise in money's own rate of return.

Proposition 2: Money and equities are substitutes.

Proof: Differentiate the demand for money with respect to $\beta_{s}$ :

$$
\frac{\partial m}{\partial \beta_{s}}=\frac{\left(J_{w} / J_{w w}\right)\left(\sigma_{b}^{2}-\rho_{s b} \sigma_{b} \sigma_{s}\right)}{\sigma_{s}^{2} \sigma_{b}^{2}\left(1-\rho_{s b}^{2}\right)}<0
$$

since $\rho_{s b}<0, \rho_{s b}^{2}<1$ and $\left(J_{w} / J_{w w}\right)<0$.

Remarks. The results confirm the traditional view that money and equities are substitutes, which implies that, as equity returns rise, economic agents hold more equity and less money.

Proposition 3: A rise in bond yields has a negative impact on the demand for money. Proof: Differentiate the demand function with respect to $\beta_{b}$ :

$$
\frac{\partial m}{\partial \beta_{b}}=\frac{\left(J_{w} / J_{w w}\right)\left(\sigma_{s}-\rho_{s b} \sigma_{b}\right)}{\sigma_{b}^{2} \sigma_{s}\left(1-\rho_{s b}^{2}\right)}<0
$$

since $\rho_{s b}<0, \rho_{s b}^{2}<1$ and $\left(J_{w} / J_{w w}\right)<0$.

Remarks. The results demonstrate that bonds and money substitute. They also confirm empirical findings in the literature that the interest elasticity of money demand is negative.

Proposition 4: The demand for money rises with real income.

Proof: Differentiate with respect to real income:

$$
\frac{\partial m}{\partial y}=\frac{\left(\frac{J_{w}}{J_{w w}}\right) \sigma_{y}\left(\rho_{b y}\left(\sigma_{b} \rho_{s b}-\sigma_{s}\right)-\rho_{s y}\left(\sigma_{s} \rho_{s b}-\sigma_{b}\right)\right)}{\sigma_{b} \sigma_{s}\left(1-\rho_{s b}^{2}\right)}>0
$$

since $\rho_{b y}<0$ and $\rho_{s y}>0$, because equity returns and economic growth are positively correlated: $\rho_{s b}<0, \rho_{s b}^{2}<1$ and $\left(J_{w y} / J_{w w}\right)<0$.

Remarks. The results confirm our intuition and validate empirical findings that the income elasticity of the money demand is positive.

Proposition 5: Changes in the volatility of the rate of return of equities has an indeterminate impact on the demand for money.

Proof: Differentiate with respect to $\sigma_{s}$ :

$$
\frac{\partial m}{\partial \sigma_{s}}=\frac{\partial A_{0}}{\partial \sigma_{s}}+\frac{\partial A_{1}}{\partial \sigma_{s}} \beta_{m}+\frac{\partial A_{2}}{\partial \sigma_{s}} \beta_{s}+A_{2} \frac{\partial \beta_{s}}{\partial \sigma_{s}}+\frac{\partial A_{3}}{\partial \sigma_{s}} \beta_{b}+\frac{\partial A_{4}}{\partial \sigma_{s}} Y
$$

but 


$$
\frac{\partial A_{0}}{\partial \sigma_{s}}=\frac{W \sigma_{p} \sigma_{b}\left(\rho_{p s}-\rho_{s b} \rho_{b p}\right)+Y \sigma_{b} \sigma_{y}\left(\rho_{s b} \rho_{b y}-\rho_{s y}\right)}{W \sigma_{b} \sigma_{b}^{2}\left(1-\rho_{s b}^{2}\right)}
$$

which is clearly indeterminate;

$$
\frac{\partial A_{1}}{\partial \sigma_{s}}=\frac{-\left(J_{w} / J_{w w}\right)\left(2 \rho_{s b} \sigma_{b} \sigma_{s}-\sigma_{b}^{2}\right)}{\sigma_{s}^{3} \sigma_{b}^{2}\left(1-\rho_{s b}^{2}\right)}<0
$$

since $\rho_{s b}<0, \quad \rho_{s b}^{2}<1$ and $\left(J_{w} / J_{w w}\right)<0$

$$
\frac{\partial A_{2}}{\partial \sigma_{s}}=\frac{\left(J_{w} / J_{w w}\right)\left(\rho_{s b} \sigma_{b} \sigma_{s}-2 \sigma_{b}^{2}\right)}{\sigma_{s}^{3} \sigma_{b}^{2}\left(1-\rho_{s b}^{2}\right)}>0
$$

since $\rho_{s b}<0, \rho_{s b}^{2}<1$ and $\left(J_{w} / J_{w w}\right)<0$

$$
A_{2} \frac{\partial \beta_{s}}{\partial \sigma_{s}}=-\rho_{s b} \sigma_{p}\left[\frac{\left(J_{w} / J_{w w}\right)\left(\sigma_{b}^{2}-\rho_{s b} \sigma_{b} \sigma_{s}\right)}{\sigma_{s}^{2} \sigma_{b}^{2}\left(1-\rho_{s b}^{2}\right)}\right]<0
$$

since $\rho_{s p}<0, \rho_{s b}<0, \quad \rho_{s b}^{2}<1$ and $\left(J_{w} / J_{w w}\right)<0$

$$
\frac{\partial A_{3}}{\partial \sigma_{s}}=\frac{\left(J_{w} / J_{w w}\right) \rho_{s b} \sigma_{b}}{\sigma_{s}^{2} \sigma_{b}^{2}\left(1-\rho_{s b}^{2}\right)}>0
$$

since $\rho_{s b}<0, \quad \rho_{s b}^{2}<1$ and $\left(J_{w} / J_{w w}\right)<0$

$$
\frac{\partial A_{4}}{\partial \sigma_{s}}=\frac{\left(J_{w} / J_{w w}\right) \sigma_{y}\left(\rho_{b y} \sigma_{b} \rho_{s b}+2 \rho_{s y} \sigma_{b}\right)}{\sigma_{b} \sigma_{s}\left(1-\rho_{s b}^{2}\right)}<0
$$

since $\rho_{s b}<0, \rho_{b y}<0, \rho_{s y}>0, \rho_{s b}^{2}<1$ and $\left(J_{w y} / J_{w w}\right)>0$.

Remarks. Equations ((38) to (43)) indicate that the sum effect of changes in the volatility of equities on the demand for money is very ambiguous. However, the impact on the coefficients of money demand is very interesting. Intuitively, one would expect that, in times of stock market volatility, money would be households' preferred store of value, because equities would be unattractive. This behaviour of households was observed in 2001 and 2002, when double-digit growth in the monetary aggregates coincided with heightened uncertainty in North American stock markets. Equations ((38) and (43)), however, show that the coefficients on the own-rate of interest and income fall with a rise in equity volatility, pulling down the demand for money. This result is a departure from the traditional view, in which the elasticities of the demand for money are held constant. We find that uncertainty in financial markets causes the parameters of the demand-for money function to move around, making it difficult to predict the full impact of household holdings of money.

Proposition 6: $A$ rise in the volatility of interest rates has an ambiguous impact on the demand for money.

Proof: Differentiate with respect to $\sigma_{b}$ :

$$
\frac{\partial m}{\partial \sigma_{b}}=\frac{\partial A_{0}}{\partial \sigma_{b}}+\frac{\partial A_{1}}{\partial \sigma_{b}} \beta_{m}+\frac{\partial A_{2}}{\partial \sigma_{b}} \beta_{s}+\frac{\partial A_{3}}{\partial \sigma_{b}} \beta_{b}+A_{3} \frac{\partial \beta_{b}}{\partial \sigma_{b}}+\frac{\partial A_{4}}{\partial \sigma_{b}} Y
$$

but 


$$
\frac{\partial A_{0}}{\partial \sigma_{b}}=\frac{W\left[\sigma_{p} \sigma_{s}\left(\rho_{b p}-\rho_{s b} \rho_{b p}\right)-\sigma_{s} \sigma_{y}\left(1-\rho_{s b}^{2}\right)\right]+Y \sigma_{s} \sigma_{y}\left(\rho_{s b} \rho_{s y}-\rho_{b y}\right)}{W \sigma_{b}^{2} \sigma_{s}\left(1-\rho_{s b}^{2}\right)}
$$

which is indeterminate.

$$
\frac{\partial A_{1}}{\partial \sigma_{b}}=\frac{-\left(J_{w y} / J_{w w}\right)\left(2 \rho_{s b} \sigma_{b} \sigma_{s}-\sigma_{s}^{2}\right)}{\sigma_{s}^{2} \sigma_{b}^{3}\left(1-\rho_{s b}^{2}\right)}<0
$$

since $\rho_{s b}<0, \rho_{s b}^{2}<1$ and $\left(J_{w} / J_{w w}\right)<0$

$$
\frac{\partial A_{2}}{\partial \sigma_{b}}=\frac{2\left(J_{w} / J_{w w}\right) \rho_{s b} \sigma_{b} \sigma_{s}}{\sigma_{s}^{2} \sigma_{b}^{3}\left(1-\rho_{s b}^{2}\right)}>0
$$

since $\rho_{s b}<0, \rho_{s b}^{2}<1$ and $\left(J_{w} / J_{w w}\right)<0$

$$
\frac{\partial A_{3}}{\partial \sigma_{b}}=\frac{\left(J_{w} / J_{w w}\right)\left(\rho_{s b} \sigma_{b}-2 \sigma_{s}\right)}{\sigma_{s} \sigma_{b}^{3}\left(1-\rho_{s b}^{2}\right)}>0
$$

since $\rho_{s b}<0, \rho_{s b}^{2}<1$ and $\left(J_{w} / J_{w w}\right)<0$

$$
A_{3} \frac{\partial \beta_{b}}{\partial \sigma_{b}}=-\rho_{b p} \sigma_{p}\left[\frac{\left(J_{w} / J_{w w}\right)\left(\sigma_{s}-\rho_{s b} \sigma_{b}\right)}{\sigma_{s} \sigma_{b}^{2}\left(1-\rho_{s b}^{2}\right)}\right]<0
$$

since $\rho_{b p}<0, \rho_{s b}<0, \quad \rho_{s b}^{2}<1$ and $\left(J_{w} / J_{w w}\right)<0$

$$
\frac{\partial A_{4}}{\partial \sigma_{b}}=\frac{\left(J_{w y} / J_{w w}\right)\left[\sigma_{s} \sigma_{y} \rho_{b y}+\sigma_{b} \rho_{s y} \rho_{s b}\right]}{\sigma_{s} \sigma_{b}^{2}\left(1-\rho_{s b}^{2}\right)}<0
$$

since $\rho_{s b}<0, \rho_{b y}<0, \quad \rho_{s y}>0, \quad \rho_{s b}^{2}<1$ and $\left(J_{w y} / J_{w w}\right)>0$

Remarks. The sign of Equation (44) is clearly indeterminate. Equations ((45) to (50)) demonstrate that changes in interest rate uncertainty cause the underlying parameters of the money demand to move in different directions, making it difficult to predict the full impact of the shock on the total quantity of money demanded by households. The results show that, when interest rates are volatile, the coefficients attached to the rates of return of alternative financial assets in the economy increase, and so push up the demand for money. On the other hand, the impact on the coefficients of the own-rate of return and income is negative, which suggests that households hold less money. The total impact depends on the net effect of the response of the changes in the parameters of the money-demand function.

Corollary. The results of propositions 5 and 6 suggest that the impact of the volatilities of monetary policy and financial markets on the demand for money produces both substitution and income effects. The substitution effect arises because, in times of uncertainty in financial markets, households prefer riskless assets, such as money, to their riskier counterparts. Economic agents demonstrate this substitution effect by raising the coefficients attached to the returns on the riskier assets. The income effect arises because, in times of financial uncertainty, agents could respond by moving away from nominal assets into real assets. As the results show, the income effect is registered through the negative relationship 
between the coefficient on income and the volatilities of the interest rate and the return on equity. The full impact of these uncertainties on the demand for money depends on the magnitude of the substitution and income effects.

Proposition 7: An increase in the volatility of income has an ambiguous impact on the demand for money.

Proof: Differentiate with respect to $\sigma_{\dot{y}}$

$$
\begin{gathered}
\frac{\partial m}{\partial \sigma_{y}}=\frac{\partial A_{0}}{\partial \sigma_{y}}+\frac{\partial A_{4}}{\partial \sigma_{y}} Y \\
\frac{\partial A_{0}}{\partial \sigma_{y}}=\frac{W\left[\sigma_{s}\left(1-\rho_{s b}^{2}\right)\right]-Y\left[\sigma_{s}\left(\rho_{s b} \rho_{s y}-\rho_{b y}\right)+\sigma_{b}\left(\rho_{s b} \rho_{b y}-\rho_{s y}\right)\right]}{W \sigma_{b} \sigma_{s}\left(1-\rho_{s b}^{2}\right)}
\end{gathered}
$$

and

$$
\frac{\partial A_{4}}{\partial \sigma_{y}}=\frac{\left(J_{w y} / J_{w w}\right)\left[\rho_{b y}\left(\sigma_{b} \rho_{s b}-\sigma_{s}\right)-\rho_{s y}\left(\sigma_{s} \rho_{s b}-\sigma_{b}\right)\right]}{W \sigma_{b} \sigma_{s}\left(1-\rho_{s b}^{2}\right)}>0
$$

since $\rho_{s b}<0, \rho_{b y}<0, \quad \rho_{s y}>0, \quad \rho_{s b}^{2}<1$ and $\left(J_{w y} / J_{w w}\right)>0$

Remarks. The results demonstrate that, in times of heightened economic uncertainty, households may or may not increase the quantity of their money holdings. An intuitive explanation for this result is that, in an uncertain economic environment, households, as a precaution, may hold excess money balances to meet unforeseen expenditures. On the other hand, economic agents may decide to hold less money and more real and financial assets. Hence, the total impact on the demand for money depends on which effect dominates.

Proposition 8: $A$ rise in the volatility of the price level has an ambiguous impact on the demand for money.

Proof: Differentiate with respect to $\sigma_{p}$ :

$$
\frac{\partial m}{\partial \sigma_{p}}=\frac{\partial A_{0}}{\partial \sigma_{p}}+A_{1} \frac{\partial \beta_{m}}{\partial \sigma_{p}}+A_{2} \frac{\partial \beta_{s}}{\partial \sigma_{p}}+A_{3} \frac{\partial \beta_{b}}{\partial \sigma_{p}}
$$

but

$$
\frac{\partial A_{0}}{\partial \sigma_{p}}=\frac{W\left[\sigma_{s}\left(\rho_{s b} \rho_{p s}-\rho_{b p}\right)-\sigma_{b}\left(\rho_{p s}-\rho_{s b} \rho_{b p}\right)\right]}{W \sigma_{b} \sigma_{s}\left(1-\rho_{s b}^{2}\right)}>0
$$

since $\rho_{s b}<0, \quad \rho_{b p}<0, \quad \rho_{p s}<0$ and $\rho_{s b}^{2}<1$

$$
A_{1} \frac{\partial \beta_{m}}{\partial \sigma_{p}}=2 \sigma_{p}\left[-\frac{\left(J_{w} / J_{w w}\right)\left(\sigma_{s}^{2}-2 \rho_{s b} \sigma_{b} \sigma_{s}+\sigma_{b}^{2}\right)}{\sigma_{s}^{2} \sigma_{b}^{2}\left(1-\rho_{s b}^{2}\right)}\right]>0
$$

since $\rho_{s b}<0, \rho_{s b}^{2}<1$ and $\left(-J_{w} / J_{w w}\right)>0$

$$
A_{2} \frac{\partial \beta_{s}}{\partial \sigma_{p}}=\left(2 \sigma_{p}-\rho_{s p} \sigma_{p}\right)\left[\frac{\left(J_{w} / J_{w w}\right)\left(\sigma_{b}^{2}-\rho_{s b} \sigma_{b} \sigma_{s}\right)}{\sigma_{s}^{2} \sigma_{b}^{2}\left(1-\rho_{s b}^{2}\right)}\right]<0
$$

since $\rho_{s p}<0, \rho_{s b}<0, \quad \rho_{s b}^{2}<1$ and $\left(J_{w} / J_{w w}\right)<0$ 


$$
A_{3} \frac{\partial \beta_{b}}{\partial \sigma_{p}}=\left(2 \sigma_{p}-\rho_{b p} \sigma_{p}\right)\left[\frac{\left(J_{w} / J_{w w}\right)\left(\sigma_{s}-\rho_{s b} \sigma_{b}\right)}{\sigma_{s}^{2} \sigma_{s}\left(1-\rho_{s b}^{2}\right)}\right]<0
$$

since $\rho_{b p}<0, \rho_{s b}<0, \quad \rho_{s b}^{2}<1$ and $\left(J_{w} / J_{w w}\right)<0$

Remarks. Clearly, the sign of Equation (54) is ambiguous. A plausible explanation for this result is that, in a volatile inflation environment, economic agents substitute out of nominal assets for real assets, causing the demand for money to fall. On the other hand, uncertain movements in the price level could increase the money held by agents for precautionary reasons to meet unplanned expenditures. Hence, the impact of the volatility of prices on the demand for money depends on which response is dominant.

\section{Conclusions}

This paper has re-examined the demand-for-money theory, because we believe that the traditional specification of money-demand functions as relationships between real money balances, a scale variable, and an opportunity cost of holding real money is very restrictive. We have argued that one of the weaknesses of the traditional demand function is the assumption that the coefficients of the explanatory variables are constant and not adequate to analyze the effects of macroeconomic uncertainty on household money holdings. Furthermore, if economic agents decide to hold money to find the proper mix for their investment portfolio, then the optimal level of money they hold will be influenced by both the level and the volatilities (variances) of the scale variable and the opportunity costs. Moreover, rational economic agents are generally risk-averse and require compensation for any additional risk they take. This suggests that the return on, and volatility of, financial assets play an important role in the quantity of money demanded by risk-averse economic agents.

Using portfolio theory, we have demonstrated theoretically that the demand for real money balances should be a function of real income and the rates of return of all financial assets traded in the economy. Unlike the traditional moneydemand relation, however, where the elasticities are assumed to be constant, the coefficients of the explanatory variables are not constant and depend on the degree of an agent's risk aversion, the volatilities of the price level and income, and the correlation of asset returns. The nature of the underlying parameters may explain why the traditional demand function has been observed empirically to be unstable. Further results in the paper have shown that the response of households to heightened volatilities in the financial markets, economic activity, and prices cannot be predicted, because a rise in general uncertainties has an ambiguous impact on money demand. This suggests that increased uncertainty is not very helpful for the planning decisions of households, because the optimal level of money holdings in the period of uncertainty cannot be ascertained.

\section{Acknowledgements}

The author would like to acknowledge the useful comments from my good 
brother, Mahamudu Bawumia, who the author has exchanged economic ideas with on countless occasions and therefore the ideas in the paper are his as well that of the author. The paper is therefore dedicated to Mahamudu. Useful comments were also received from anonymous referees. This paper was finalized during author's last visit to Banjul, The Gambia in November 2017. The author is very grateful to Mrs. Peggy Janneh for her exceptional hospitality and courtesies in making him very comfortable in Banjul. However, any errors or omissions must be attributed to the author. Of course, the views expressed in this paper are those of the author and should not be attributed to the United Nations.

\section{References}

[1] Keynes, J.M. (1936) The General Theory of Employment, Interest and Money. Macmillan, New York.

[2] Baumol, W. (1952) The Transactions Demand for Cash: An Inventory Theoretical Approach. Quarterly Journal of Economics, 66, 545-556. https://doi.org/10.2307/1882104

[3] Tobin, J. (1958) Liquidity Preference as Behaviour towards Risk. Review of Economics Studies, 25, 68-85. https://doi.org/10.2307/2296205

[4] Clower, R. (1967) A Reconsideration of the Microeconomic Foundation of Monetary Theory. Western Economic Journal, 6, 1-8.

[5] Akerloff, G.A. and Milbourne, R.D. (1980) The Short Run Demand for Money. Economic Journal, 90, 885-900. https://doi.org/10.2307/2231748

[6] Frenkel, J.A. and Jovanovic, B. (1980) On the Transactions and Precautionary Demand for Money. Quarterly Journal of Economics, 95, 25-43. https://doi.org/10.2307/1885347

[7] Laidler, D.E. (1993) The Demand for Money: Theories, Evidence, and Problems. 4th Edition, Harper Collins College Publishers, New York.

[8] Tweneboah, G. and Alagidede, P. (2018) Currency Substitution and Stability of Money Demand in Ghana. The Journal of Developing Areas, 52, 41-53. https://doi.org/10.1353/jda.2018.0021

[9] Bafile, R. and Piergallini, A. (2011) Firms' Money Demand and Monetary Policy. Munich Personal RePEc Archive Working Papers.

[10] Arnold, I. and Roelands, S. (2010) The Demand for Euros. Journal of Macroeconomics, 32, 674-684. https://doi.org/10.1016/j.jmacro.2010.01.001

[11] Dobnik, F. (2013) Long-Run Money Demand in OECD Countries: What Role Do Common Factors Play? Empirical Economics, 45, 89-113. https://doi.org/10.1007/s00181-012-0600-6

[12] Dreger, C. and Wolters, J. (2015) Unconventional Monetary Policy and Money Demand. Journal of Macroeconomics, 46, 40-54. https://doi.org/10.1016/j.jmacro.2015.07.005

[13] Andrew, A.P. (1899) What Ought to Be Called Money. Quarterly Journal of Economics, 13, 219-227. https://doi.org/10.2307/1882201

[14] Black, F. (1970) Banking and Interest Rates in a World Without Money. Journal of Bank Research, 1, 8-20.

[15] Fama, E.F. (1980) Banking in the Theory of Finance. Journal of Monetary Economics, 6, 39-57. https://doi.org/10.1016/0304-3932(80)90017-3 
[16] Keynes, J.M. (1930) Treatise on Money. Harcourt, Brace and Company, New York.

[17] Friedman, M. (1956) The Quantity Theory of Money-A Restatement. In: Studies in the Quantity Theory of Money, University of Chicago Press, Chicago, 3-21.

[18] Friedman, M. and Schwartz, A.J. (1970) Monetary Aggregates of the United States Estimates, Sources and Methods. Columbia Press, New York.

[19] United Kingdom Parliament (1959) Committee on the Working of the Monetary System Report. Radcliffe Report, 827.

[20] Hicks, J.R. (1962) Liquidity. Economic Journal, 72, 787-802. https://doi.org/10.2307/2228351

[21] Shearer, R.A., Chant, J.F. and Bond, D.E. (1984) The Economics of the Canadian Financial Systems: Theory, Policy and Institutions. 2nd Edition, Prentice-Hall, Scarborough.

[22] Clower, R.W. (1971) Theoretical Foundation of Monetary Policy. In: Clayton, G., Gilbert, J.C. and Sedgwick, R., Eds., Monetary Theory and Monetary Policy in the 1970s, Oxford University Press, London, 13-28.

[23] Shackle, G.L.S. (1971) Discussion: Theoretical Foundation of Monetary Policy. In: Clayton, G., Gilbert, J.C. and Sedgwick, R., Eds., Monetary Theory and Monetary Policy in the 1970s, Oxford University Press, London, 32-34.

[24] Johnson, H.G. (1971) Discussion: Theoretical Foundation of Monetary Policy. In: Clayton, G., Gilbert, J.C. and Sedgwick, R., Eds., Monetary Theory and Monetary Policy in the 1970s, Oxford University Press, London, 29-31. https://doi.org/10.1007/978-3-642-46259-7_9

[25] Osborne, D.K. (1984) Ten Approaches to the Definition of Money. Federal Reserve Bank of Dallas Economic Review, 1-23.

[26] Friedman, M. and Meiselman, D. (1963) The Relative Stability of Monetary Velocity and the Investment Multiplier in the United States, 1897-1958. In: Stabilization Policies, Prentice-Hall, Englewood, 165-268.

[27] Mason, W.E. (1976) The Empirical Definition of Money: A Critique. Economic Inquiry, 14, 525-538. https://doi.org/10.1111/j.1465-7295.1976.tb00440.x

[28] Lucas, R.E. (1976) Econometric Policy Evaluation: A Critique. In: Brunner, K. and Meltzer, A.H., Eds., The Phillips Curve and Labour Markets, Chicago University Press, Chicago, 19-46. https://doi.org/10.1016/S0167-2231(76)80003-6

[29] Kaufman, G. (1969) More on an Empirical Definition of Money. American Economic Review, 59, 78-87.

[30] Laidler, D. (1969) The Definition of Money: Theoretical and Empirical Problems. Journal of Money, Credit and Banking, 1, 508-525. https://doi.org/10.2307/1991204

[31] Cooley, T.F. and Leroy, S.F. (1981) Identification and Estimation of Money Demand. American Economic Review, 71, 825-844.

[32] Merton, R.C. (1971) Optimum Consumption and Portfolio Rules in a Continuous-Time Model. Journal of Economic Theory, 3, 373-413. https://doi.org/10.1016/0022-0531(71)90038-X

[33] Merton, R.C. (1973) An Intertemporal Assets Pricing Model. Econometrica, 41, 867-887. https://doi.org/10.2307/1913811

[34] Fischer, S. (1975) The Demand for Index Bonds. Journal of Political Economy, 83, 509-534. https://doi.org/10.1086/260339

[35] Malliaris, A.G. and Brock, W.A. (1982) Stochastic Methods in Economics and Finance. North-Holland, Amsterdam. 


\section{Appendix}

\section{A1. Expressing Returns in Real Terms}

In an inflationary economy, economic agents are more concerned with the real return on an asset than the nominal return. Hence, we apply Itô's lemma to find the expressions for the real return of the assets in the economy. Define the real value of bonds as:

$$
b=\frac{B}{P}
$$

where $B$ is the nominal value of the bonds and $P$ is the price index. Since we have a one-good economy, however, the price index is the same as the price of the consumption good. Applying Itô's lemma, we get the following:

$$
\mathrm{d} b=\frac{\partial b}{\partial t} \mathrm{~d} t+\frac{\partial b}{\partial B} \mathrm{~d} B+\frac{\partial b}{\partial P} \mathrm{~d} P+0.5 \frac{\partial^{2} b}{\partial B^{2}}(\mathrm{~d} B)^{2}+0.5 \frac{\partial^{2} b}{\partial P^{2}}(\mathrm{~d} P)^{2}+0.5 \frac{\partial^{2} b}{\partial B \partial P} \mathrm{~d} B \mathrm{~d} P(\mathrm{~A} 2)
$$

Taking the appropriate partial differentials of $b$ and substituting Equations ((1) and (4)) from the text, Equation (A2) becomes:

$$
\begin{aligned}
\mathrm{d} b= & \frac{1}{P}\left[\alpha_{b} B \mathrm{~d} t+\sigma_{b} B \mathrm{~d} z_{b}\right]-\frac{B}{P^{2}}\left[\alpha_{p} P \mathrm{~d} t+\sigma_{p} P \mathrm{~d} z_{p}\right] \\
& +\frac{B}{P^{3}}\left[\sigma_{p}^{2} P^{2} \mathrm{~d} t\right]-\frac{1}{P^{2}}\left[\rho_{b p} \sigma_{b} \sigma_{p} P B\right] \mathrm{d} t
\end{aligned}
$$

Separating out the drift and the diffusion terms, Equation (A3) becomes:

$$
\frac{\mathrm{d} b}{b}=\beta_{b} \mathrm{~d} t+\sigma_{b} \mathrm{~d} z_{b}-\sigma_{p} \mathrm{~d} z_{p}
$$

with

$$
\beta_{b}=\alpha_{b}-\alpha_{p}-\sigma_{b p}+\sigma_{p}^{2}
$$

and $\sigma_{b p}$, which is the covariance between the nominal rate of return on money and the inflation rate, is defined as:

$$
\sigma_{b p}=\rho_{b p} \sigma_{b} \sigma_{p}
$$

In a similar manner, we define the real values of the portfolios for equities and money as:

$$
\begin{gathered}
s=\frac{S}{P} \\
m=\frac{M}{P}
\end{gathered}
$$

The application of Itô's lemma yields the expressions for real returns for the portfolios as:

$$
\begin{gathered}
\frac{\mathrm{d} s}{s}=\beta_{s} \mathrm{~d} t+\sigma_{s} \mathrm{~d} z_{s}-\sigma_{p} \mathrm{~d} z_{p} \\
\frac{\mathrm{d} m}{m}=\beta_{m} \mathrm{~d} t-\sigma_{p} \mathrm{~d} z_{p}
\end{gathered}
$$

where 


$$
\begin{gathered}
\beta_{s}=\alpha_{s}-\alpha_{p}-\sigma_{s p}+\sigma_{p}^{2} \\
\beta_{m}=\alpha_{m}-\alpha_{p}+\sigma_{p}^{2}
\end{gathered}
$$

and $\sigma_{s p}$, which is the covariance between the nominal rate of return on equity and the inflation rate, is defined as:

$$
\sigma_{s p}=\rho_{s p} \sigma_{s} \sigma_{p}
$$

\section{A2. The Dynkin Operator}

A representative household's optimization problem can be summarized as:

$$
\max _{c, \omega_{1}, \omega_{2}} E_{00}\left[\int_{0}^{\infty} \mathrm{e}^{-\rho t} U(c(t), t) \mathrm{d} t\right]
$$

subject to the budget constraint defined in the text (Equation (17)), and

$$
W(0)=W_{0}
$$

Also, the utility function $U(\cdot, \cdot)$ is restricted to be concave in $c\left(\right.$ i.e., $U_{c}>0$ and $\left.U_{c c}<0\right) . E_{0}$ is the conditional expectations operator conditional on $W(0)=W_{0}$ being known. Let $t=t_{0}+\Delta t$ and assume that the third partial derivatives of $J(\cdot)$ are bounded. Then, by applying Taylor's series theorem, the mean value theorem for integrals, and taking the limits as $\Delta t \rightarrow 0$, define a value function, $J$, as:

$$
\begin{aligned}
& J\left(W\left(t_{0}\right), Y, t_{0}\right) \\
& \equiv \max _{c, \omega_{1}, \omega_{2}}\left[\mathrm{e}^{-\rho t} U(c(t), t)+E\left(J\left(W\left(t_{0}\right), Y, t_{0}\right)\right)+J_{t} \mathrm{~d} t+J_{w} E(\mathrm{~d} W)\right. \\
& \left.+J_{y} E(\mathrm{~d} Y)+J_{w y} E(\mathrm{~d} W \mathrm{~d} Y)+\frac{1}{2} J_{w w} E(\mathrm{~d} W)^{2}+\frac{1}{2} J_{y y} E(\mathrm{~d} Y)^{2}\right]
\end{aligned}
$$

From the real income relation (Equation (14)) and the budget constraint (Equation (16)), we have:

$$
\begin{aligned}
E(\mathrm{~d} W)= & \omega_{1} W\left(\beta_{b}-\beta_{m}\right)+\omega_{2} W\left(\beta_{s}-\beta_{m}\right)+\left(\beta_{m} W-c\right)+\beta_{y} Y \\
E(\mathrm{~d} W)^{2}= & W^{2}\left(\omega_{1}^{2} \sigma_{b}^{2}+\omega_{2}^{2} \sigma_{s}^{2}+2 \omega_{1} \omega_{2} \sigma_{b s}-2 \omega_{1} \sigma_{b p}-2 \omega_{2} \sigma_{s p}+\sigma_{p}^{2}\right) \\
& +W Y\left(2 \omega_{1} \sigma_{b y}+2 \omega_{2} \sigma_{s y}-2 \sigma_{p y}+Y \sigma_{y}^{2}\right)
\end{aligned}
$$

but

$$
\begin{gathered}
E(\mathrm{~d} Y)=\beta_{y} Y \\
E(\mathrm{~d} Y)^{2}=\sigma_{y}^{2} Y^{2} \\
E(\mathrm{~d} Y \mathrm{~d} W)=W Y\left(\omega_{1} \sigma_{b y}+\omega_{2} \sigma_{s y}-\sigma_{y p}+Y \sigma_{y}^{2}\right) \\
E\left(J\left(W\left(t_{0}\right), Y, t_{0}\right)\right) \equiv J\left(W\left(t_{0}\right), Y, t_{0}\right)
\end{gathered}
$$

Substituting Equations ((A17) to (A22)) into Equation (A16), we obtain the continuous time version of the Bellman-Dreyfus fundamental optimality equation of the form:

$$
\max _{c, \omega_{1}, \omega_{2}} \Phi\left(c, \omega_{1}, \omega_{2}, W, Y, t\right)=\mathrm{e}^{-\rho t} U(c(t), t)+L(J)
$$


where $L$, which is known as the Dynkin operator over $W$ and $Y$, is defined as:

$$
\begin{aligned}
L(J)= & J_{t}+J_{w}\left[\omega_{1} W\left(\beta_{b}-\beta_{m}\right)+\omega_{2} W\left(\beta_{s}-\beta_{m}\right)+\left(\beta_{m} W-c\right)+\beta_{y} Y\right] \\
& +J_{y} \beta_{y} Y+J_{w y}\left[W Y\left(\omega_{1} \sigma_{b y}+\omega_{2} \sigma_{s y}-\sigma_{y p}+Y \sigma_{y}^{2}\right)\right] \\
& +0.5 J_{w w}\left[W^{2}\left(\omega_{1}^{2} \sigma_{b}^{2}+\omega_{2}^{2} \sigma_{s}^{2}+2 \omega_{1} \omega_{2} \sigma_{b s}-2 \omega_{1} \sigma_{b p}-2 \omega_{2} \sigma_{s p}+\sigma_{p}^{2}\right)\right. \\
& \left.+W Y\left(2 \omega_{1} \sigma_{b y}+2 \omega_{2} \sigma_{s y}-2 \sigma_{p y}+Y \sigma_{y}^{2}\right)\right]+0.5 J_{y y} \sigma_{y}^{2} Y^{2}
\end{aligned}
$$

Constrained by the budget equation, equation (A23) is the household optimization problem.

\section{A3. Demand for financial Assets}

The demand for the three financial assets of the economy is derived by solving first-order conditions summarized by Equations ((22) and (23)) for $\omega_{1}, \omega_{2}$, and $\omega_{3}$. The expressions for the functions are:

$$
\begin{aligned}
\omega_{1}= & -\frac{J_{w}}{W J_{w w}}\left[\frac{\left(\beta_{b}-\beta_{m}\right)}{\sigma_{b}^{2}\left(1-\rho_{s b}^{2}\right)}-\frac{\rho_{s b}\left(\beta_{s}-\beta_{m}\right)}{\sigma_{b} \sigma_{s}\left(1-\rho_{s b}^{2}\right)}\right]+\frac{Y J_{w y}}{W J_{w w}}\left(\frac{\sigma_{y}\left(\rho_{s b} \rho_{s y}-\rho_{b y}\right)}{\sigma_{b}\left(1-\rho_{s b}^{2}\right)}\right) \\
& +\frac{Y \sigma_{y}\left(\rho_{s b} \rho_{s y}-\rho_{b y}\right)+W \sigma_{p}\left(\rho_{b p}-\rho_{s b} \rho_{p s}\right)}{W \sigma_{b}\left(1-\rho_{s b}^{2}\right)} \\
\omega_{2}= & -\frac{J_{w}}{W J_{w w}}\left[\frac{\left(\beta_{s}-\beta_{m}\right)}{\sigma_{s}^{2}\left(1-\rho_{s b}^{2}\right)}-\frac{\rho_{s b}\left(\beta_{b}-\beta_{m}\right)}{\sigma_{b} \sigma_{s}\left(1-\rho_{s b}^{2}\right)}\right]+\frac{Y J_{w y}}{W J_{w w}}\left(\frac{\sigma_{y}\left(\rho_{s b} \rho_{b y}-\rho_{s y}\right)}{\sigma_{s}\left(1-\rho_{s b}^{2}\right)}\right) \\
& +\frac{Y \sigma_{y}\left(\rho_{s b} \rho_{b y}-\rho_{s y}\right)+W \sigma_{p}\left(\rho_{p s}-\rho_{s b} \rho_{b p}\right)}{W \sigma_{s}\left(1-\rho_{s b}^{2}\right)} \\
\omega_{3}= & \left.-\frac{J_{w}\left[\frac{\left(\sigma_{b} \rho_{s b}-\sigma_{s}\right)\left(\beta_{b}-\beta_{m}\right)}{W J_{w w}}-\frac{\left(\sigma_{s} \rho_{s b}-\sigma_{b}\right)\left(\beta_{b}-\beta_{m}\right)}{\sigma_{s} \sigma_{b}^{2}\left(1-\rho_{s b}^{2}\right)}\right]}{\sigma_{s}^{2}\left(1-\rho_{s b}^{2}\right)}\right] \\
& +\left(-\frac{Y J_{w y}}{W J_{w w}}\left[\frac{\sigma_{s} \sigma_{y}\left(\rho_{s b} \rho_{s y}-\rho_{b y}\right)-\sigma_{b} \sigma_{y}\left(\rho_{s b} \rho_{b y}-\rho_{s y}\right)}{\sigma_{s b}\left(1-\rho_{s m}^{2}\right)}\right]\right) \\
& +\frac{W\left[\sigma_{s} \sigma_{y}\left(1-\rho_{s b}^{2}\right)-\sigma_{p} \sigma_{s}\left(\rho_{b p}-\rho_{s b} \rho_{p s}\right)-\sigma_{p} \sigma_{b}\left(\rho_{p s}-\rho_{s b} \rho_{b p}\right)\right]}{W \sigma_{b} \sigma_{s}\left(1-\rho_{s b}^{2}\right)} \\
& -\frac{Y \sigma_{y}\left[\sigma_{s}\left(\rho_{s b} \rho_{s y}-\rho_{b y}\right)+\sigma_{b}\left(\rho_{s b} \rho_{b y}-\rho_{s y}\right)\right]}{W \sigma_{b} \sigma_{s}\left(1-\rho_{s b}^{2}\right)}
\end{aligned}
$$

